\title{
THE CEREBRAL AND PERIPHERAL UPTAKE OF AMMONIA IN LIVER DISEASE WITH AN HYPOTHESIS FOR THE MECHANISM OF HEPATIC COMA ${ }^{1,2}$
}

\author{
By SAMUEL P. BESSMAN 3 ANd ALICE N. BESSMAN 4
}

(From the Research Foundation of Children's Hospital, Washington, D. C.)

(Submitted for publication August 2, 1954 ; accepted December 15, 1954)

Hepatic coma is a frequent terminal event in cirrhosis of the liver. Interest in its pathogenesis and treatment has been stimulated by recent observations that there is some relation between the increased blood ammonia level and the development of coma $(2-4)$.

1 Supported by grants from the Playtex Park Foundation, the National Institutes of Health, and the International Minerals and Chemicals Co.

2 Presented in part at the Federation of Biological Scientists, Atlantic City, New Jersey, May, 1954 (1).

3 Present Address: Dept. of Pediatrics, University of Maryland Medical School, Baltimore 1, Md.

4 Fellow in Medicine, George Washington University Medical School.
In the course of a series of observations of the cerebral blood flow and oxygen uptake in a number of diseases, the cerebral arteriovenous difference of ammonia was also measured to test a hypothesis for the chemical mechanism of hepatic coma. This report deals with the cerebral and peripheral arteriovenous differences of ammonia in patients with cirrhosis of the liver, and in several other conditions.

\section{METHODS}

Arterial blood was obtained by femoral artery puncture and cerebral venous blood by cannulation of the jugular bulb by standard methods. Peripheral venous blood was

TABLE I-A

Patients without hepatic disease, blood ammonia, gamma per ml.

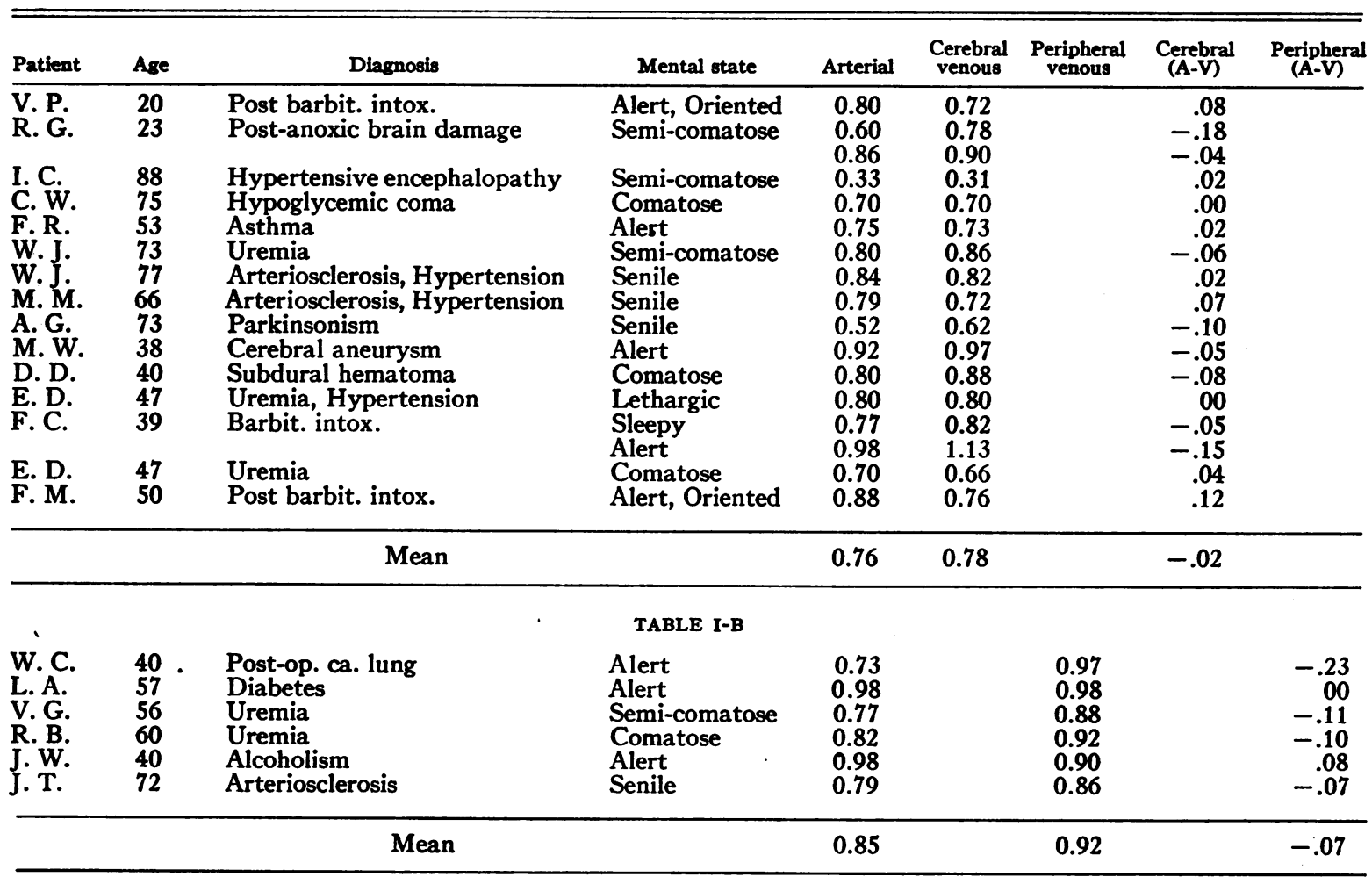

23 Observations on 21 Patients 
TABLE II-A

Patients with hepatic disease, blood ammonia in gamma per ml.

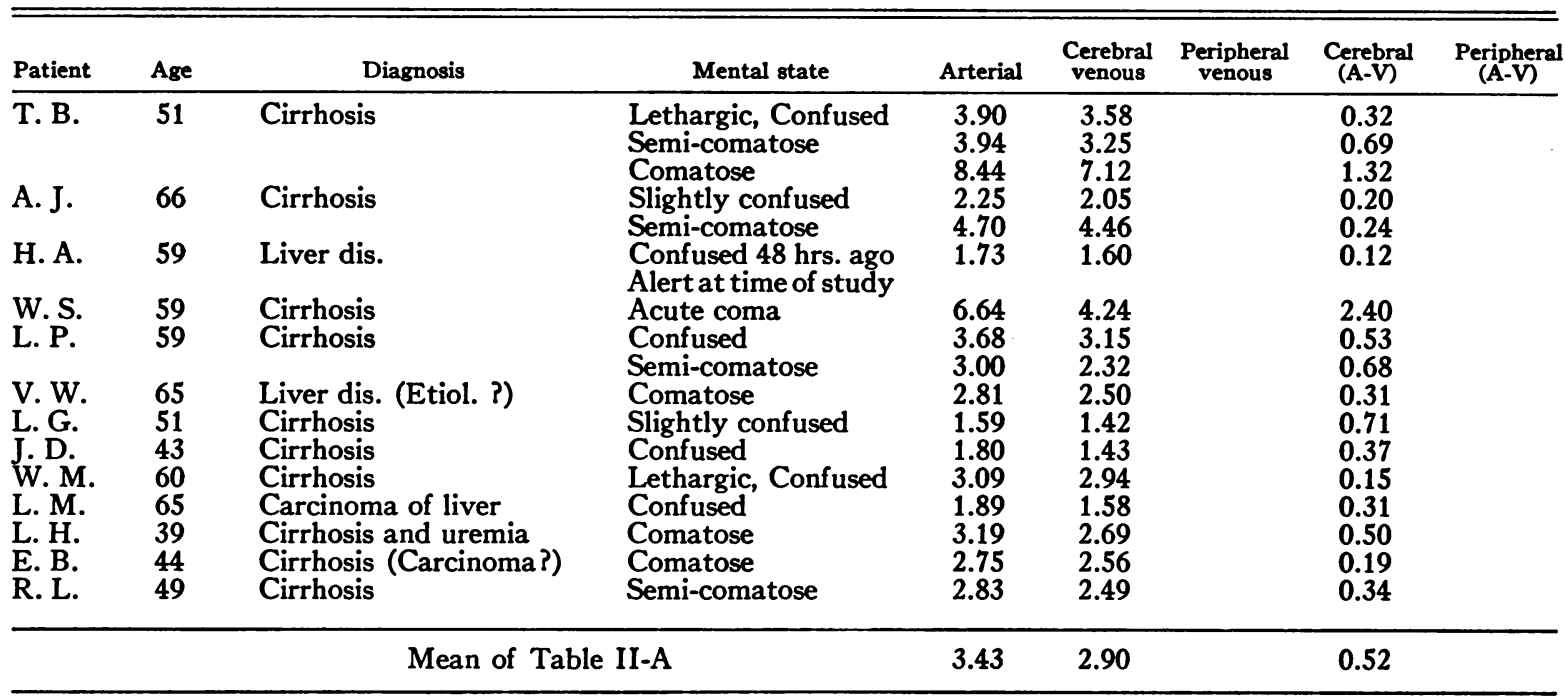

TABLE II-B

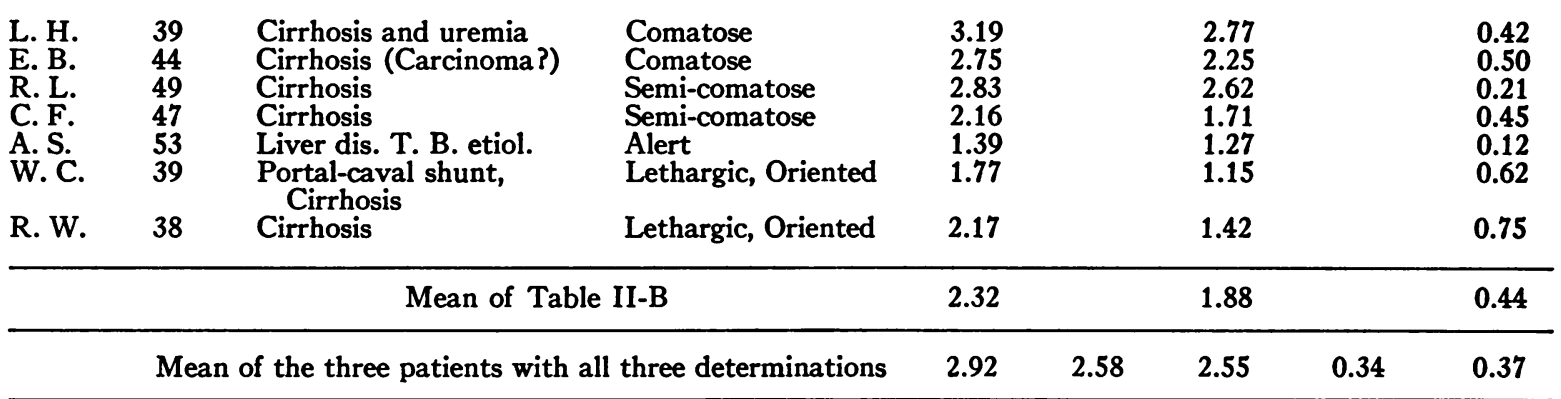

drawn from the antecubital fossa. Ammonia determinations were made by the method of Seligson and Seligson (5) modified in the following manner to permit measurement of smaller amounts of ammonia. The diffusion vessels $(15 \mathrm{ml}$. penicillin vial stoppered with the standard diaphragm stopper through which was passed a $3 \mathrm{~mm}$. in diameter glass rod enlarged at the tip to a $6 \mathrm{~mm}$. ball) were loaded with $1.0 \mathrm{ml}$. of saturated potassium carbonate. The rods were dipped into normal sulphuric acid and replaced in the vials. Blood was taken without stasis into a $2 \mathrm{ml}$. syringe and ejected from the syringe, $1 \mathrm{ml}$. into each of two vials. They were re-stoppered immediately and placed horizontally on a rotating wheel which revolved at a frequency of 40 R.P.M. At the end of thirty minutes' rotation, the vials were removed from the wheel and the glass rods plunged into $1.5 \mathrm{ml}$. of Nessler's solution (6) diluted 1:10 with ammonia free (Permutit treated) distilled water contained in $1 \mathrm{~cm}$. cuvettes for the Coleman Junior Spectrophotometer. The stopper was pressed tightly against the mouth of the cuvette and the cuvette inverted to assure mixing. The optical density was read at the end of ten minutes at a wave length of 500 millimicrons. Duplicate standards were run simultaneously, and all values calculated on the basis of these standards. Duplicates of the blood samples were also run in all cases. Half milliliter aliquots of blood were used when the ammonia level was expected to be high (1 ml. syringe). No correction for diffusion difference between blood and standard was applied.

Patients were volunteers or comatose patients.

\section{RESULTS}

Table I-A gives the arterial and cerebral venous ammonia levels in 13 patients (15 observations) with a variety of conditions, not including any known hepatic disorder. Table I-B shows the arterial and peripheral venous ammonia levels in six patients without liver disease. It is clear that the blood levels of ammonia by this method cover only a narrow range and that normal individuals, or those not suffering from liver disease, have ammonia nitrogen levels of 1 microgram per $\mathrm{ml}$. or less by this method.

Table II-A gives the arterial and cerebral venous ammonia levels in 13 patients (17 observa- 


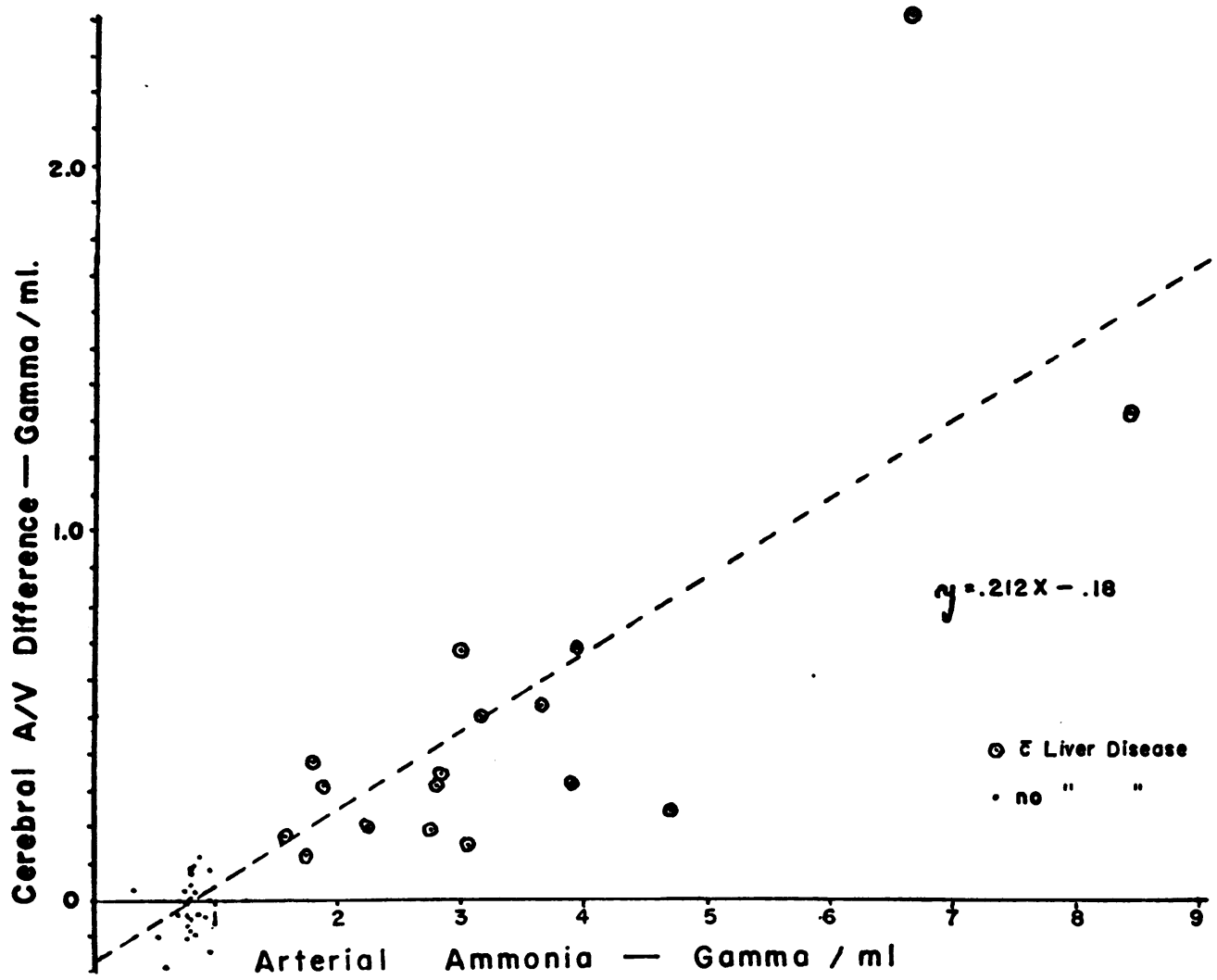

Fig. 1. The Reintion of the Cerebral Arteriovenous Difference of Ammonia to the Arterial Lever

Correlation coefficient for these data is $\mathbf{0 . 8 2}$.

TABLE III

Liver function studies of patients in Table II

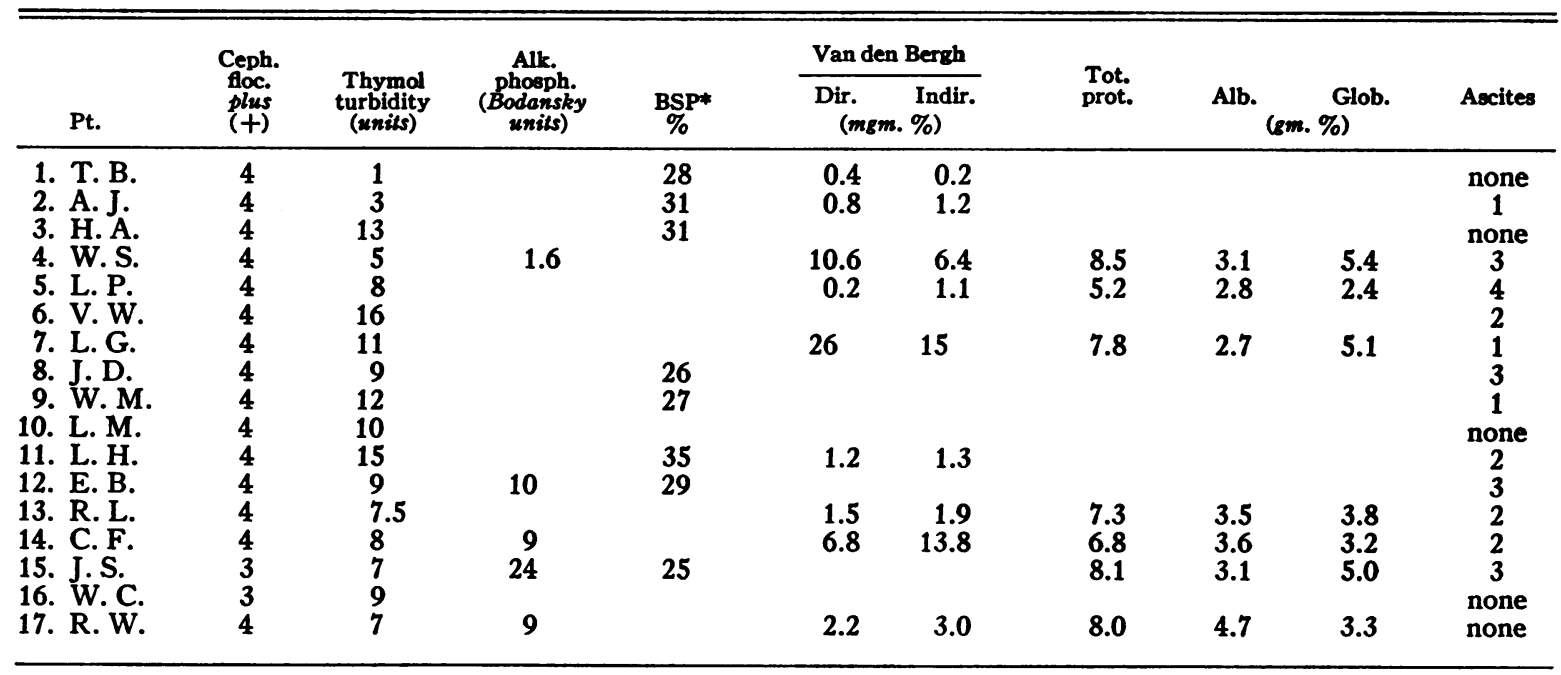

* BSP $=$ Bromsulfalein retention at 45 minutes after $5 \mathrm{mgm}$. per $\mathrm{kg}$. dose administered intravenously. 
tions) with liver disease, both comatose and noncomatose. The last three cases of Table II-A are included as the first three cases of Table II-B. In these three cases, arterial, peripheral and cerebral venous blood samples were drawn within five minutes of each other and all measured for ammonia content. In all cases, whether the patient was comatose or not, the blood values for ammonia were elevated above normal. In no case was there a negative cerebral arteriovenous difference: the final figures in Table II-B give the average levels of the three patients in whom the arterial, cerebral and peripheral ammonia levels were measured simultaneously, and the values for peripheral and cerebral arteriovenous differences are nearly the same. The degree of coma, assessed clinically, is roughly proportional to the level of ammonia, and for two patients (T. B. and A. J.) the levels of ammonia parallel the development of coma. Figure 1 is a plot of all the arteriovenous differences of ammonia nitrogen of Tables I and II against the arterial blood level of ammonia nitrogen. The uptake of ammonia by the brain shows a striking correlation to the level of ammonia nitrogen entering the brain.

Table III presents various liver function studies done on patients in Table II. All these subjects had moderate to severe impairment of hepatic function by these various tests. However, no one test paralleled the mental state of the patient as closely as the arterial blood ammonia level.

\section{DISCUSSION}

The results presented confirm the recently reported observations of McDermott and Adams (2) who reported that the appearance of abnormal neurological signs shown by a patient with cirrhosis of the liver and Eck fistula paralleled changes in the blood ammonia levels.

The data reported here are also consistent with the data of Phillips, Schwartz, Gabuzda, and Davidson (3), if the differences in method are taken into consideration. The values reported by that group as normal ( 1.0 to 3.0 gamma per ml.) are far higher than the values of Conway (7), which might, from the standpoint of technique, be considered to be more accurate indices of the true blood ammonia. Our normal values fall close to the Conway range and never enter the range reported by the above (3) investigators. This suggests that the extraneous nucleotide ammonia, increasing amounts of which are determined as free ammonia as the diffusion time is prolonged, may mask changes in free blood ammonia which have profound significance in the development of coma. The five patients (A. D., J. M., C. J., E. B., and J. B.) on whom the above investigators ( 3 ) made determinations during "impending coma" and coma, show a mean increase from the first to the second state of 1.4 gamma per ml. Only one of them (C. J.) showed a fall in blood ammonia, and this was only 0.4 gamma per $\mathrm{ml}$. which could lie within the experimental error of their method.

The positive A-V difference of free ammonia shown by the data presented in this report lead to the conclusion that free blood ammonia is converted by brain and muscle to a bound form which is no longer detectable by the method employed. This "utilization" of free ammonia by brain in hepatic coma suggests an hypothesis concerning the pathologic chemistry of this syndrome. The fact that ammonia is taken up by brain and that it is not in physical equilibrium with brain tissue, which would be the case if the arteriovenous difference were zero (as it is in patients without liver disease), indicates that ammonia is being utilized in some chemical reaction. Of the many reactions

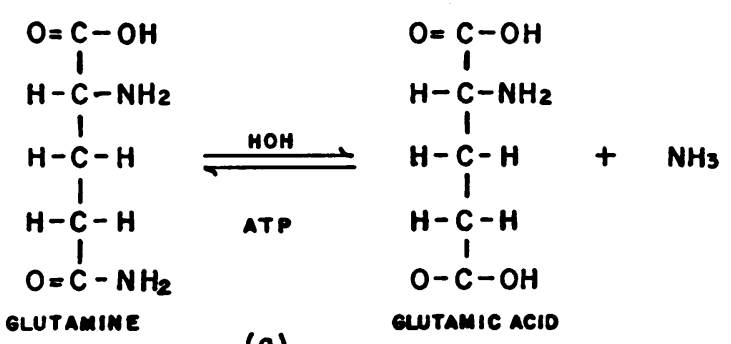

(a)

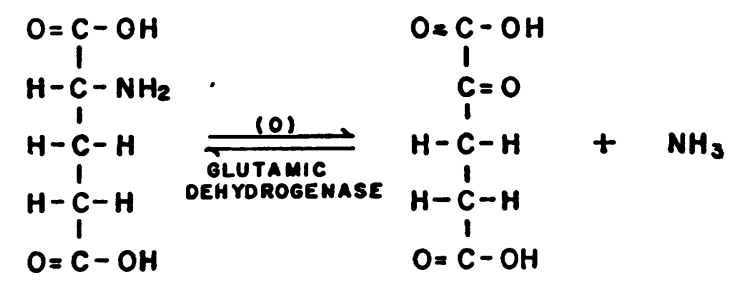

(b)

$\propto$ Ketoglutaric acio

Fig. 2. The Major Reactions Forming, or Utimizing, Ammonia in Brain 
utilizing ammonia in the body, two are of significance in the brain-glutamine synthesis, and the reversal of glutamate oxidation, namely reductive amination of alpha ketoglutarate, Figure 2.

Glutamine synthesis could account for the high uptake of ammonia, and there is no doubt that at approximately 0.01 molar (8) there is sufficient glutamate in brain to supply a fair amount for the synthesis initially to take place. The requirement of ATP for the synthesis of glutamine might at first glance suggest that this could be the cause of the coma, by taking ATP from supplies necessary for other cerebral activities. This explanation is not, however, consistent with the mass of experimental data which shows that the removal of ATP from an oxidizing system does not inhibit the system, but rather stimulates it to further oxidative activity (9-11). Thus, if we are dealing merely with glutamine synthesis, we should find the oxygen uptake of the brain in hepatic coma increased. In addition, in spite of the preformed glutamic acid present in brain, it would not be long, even at a rate of utilization of ammonia of only 1 microgram per ml. to exhaust the total brain glutamate. (At a rate of cerebral blood flow of $55 \mathrm{ml}$. per $100 \mathrm{~g}$. per min., such a difference would imply an uptake of almost four micromoles of ammonia per minute per $100 \mathrm{gm}$. or a loss of glutamate at the same rate.)

On the other hand, the synthesis of glutamate, Figure 2 (b), from alpha ketoglutarate could

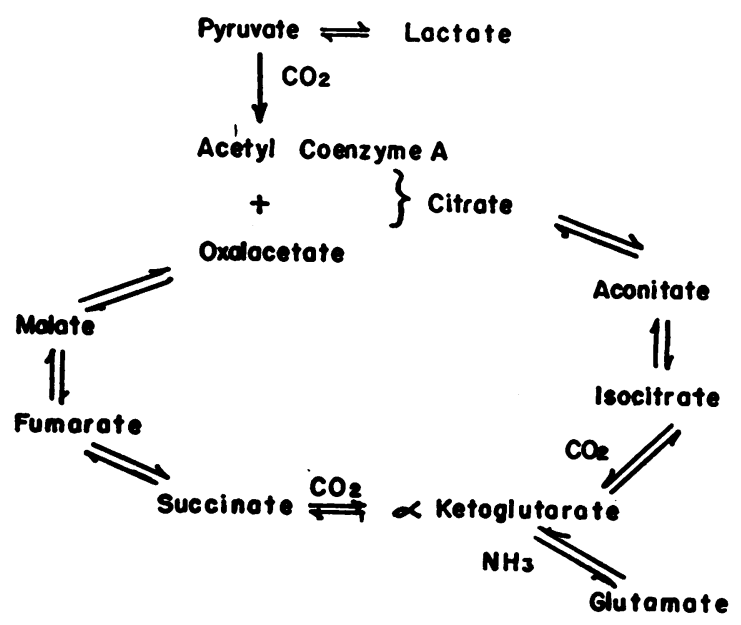

Fig. 3. The Krebs Cycle

A number of intermediate steps not pertinent to the discussion have been omitted. produce the phenomena seen in hepatic coma. To elucidate this more clearly we must refer to the Krebs cycle (Figure 3 ) which is the most likely final oxidative pathway in brain. The features of this cycle pertinent to this hypothesis are that the cycle is regenerative, requiring only minimal concentrations of any member at any time, and that alpha ketoglutarate is an essential member. It is apparent that any reaction which would tend to remove alpha ketoglutarate would also diminish the rate of formation of the succeeding members of the cycle. Since a major portion of the oxidative phosphorylation of brain is derived from the Krebs cycle, oxygen utilization and the formation of metabolic energy (high energy phosphate) will be diminished in direct proportion to the reduction in ketoglutarate available for the cycle. Both the decreased oxygen uptake and the utilization of ammonia by brain are part of the picture of hepatic coma. Wechsler, Crum, and Roth (12) report a greater depression of cerebral metabolism than of cerebral blood flow in hepatic coma and postulate that the "results implicate an intra cellular metabolic abnormality in the brain as a cause for the reduction in cerebral metabolism and coma in severe liver disease." Fazekas and Bessman (13) have found similar depression of cerebral oxygen consumption in patients who are semicomatose or comatose due to liver disease.

The finding of some increase in the glutamate leaving the brain when ammonia is entering (1) is corroborative of the hypothesis that the lesion in ammonia intoxication is a reversal of the glutamic dehydrogenase reaction with resultant formation of glutamate by brain. Von Euler, Adler, Günther, and Das (14) have shown that the equilibrium for reaction II(b) is far to the left and that a very low concentration of ammonia can push the reaction over to net synthesis of glutamate.

This mechanism of action of ammonia has been studied by Potter and Recknagel (15) who showed that the in vitro inhibition of tissue respiration by ammonium chloride was accompanied by accumulation of glutamic and aspartic acids. The further possible effects of a glutamic acid excess so produced are suggested by experiments reported from this laboratory $(16,17)$.

The uptake of ammonia by muscle is to be expected in view of the fact that the Krebs cycle is operative here as well as in brain, and that there 
is an active glutamic dehydrogenase system in muscle.

Although the evolution of ammonia from muscle on exertion has been traced to deamination of adenine nucleotides (18), no comparable study has been made of the uptake of ammonia by muscle when the blood ammonia is elevated. It is of clinical significance in two ways. It explains the high level of glutamate found in the blood of patients with hepatic coma (19). In addition, it suggests that in the presence of an elevated arterial ammonia, the measurement of venous ammonia gives a false value for the ammonia level in the blood reaching the brain. This difference between arterial and peripheral venous ammonia would be of qualitative importance in the understanding of borderline cases since there would conceivably be sufficient uptake of ammonia by muscle to mask an elevated arterial level, and of quantitative significance in comparative studies of blood ammonia as related to clinical phenomena of hepatic coma.

A word might be said relative to a possibly broader significance of blood ammonia in the coma and cerebral symptoms of other diseases. For example, Nelson's and Seligson's extensive study of blood ammonia in experimental shock (20) clearly demonstrates an uptake of ammonia by brain. The high levels of glutamic acid found in the blood of patients with many types of wasting disease, particularly malignancy (21), suggest a possibly fruitful investigation of the relation of ammonia to cerebral symptoms in these diseases. Preliminary studies in our laboratories reveal elevated blood ammonia levels in patients with cardiac failure, and may implicate ammonia in the cerebral symptomatology of cardiac (22) disease.

From the standpoint of therapy there are several factors which must be considered. It has been reported that the blood level of alpha ketoglutaric acid is increased in hepatic coma (23). At first glance this would seem incompatible with any theory which postulated diminished levels of this intermediate in the brain. Alpha ketoglutarate, however, being a dibasic acid, is not taken up by the brain, and lack of this compound could well exist behind the "blood brain barrier." This keto acid could be a therapeutic agent and probably does act in muscle to ameliorate the high levels of blood ammonia by the same reaction which is excessive in brain, namely, the reductive amination to glutamate. The high levels of blood ketoglutarate probably result from the inability of the damaged liver to oxidize the intermediate products of fat, protein, and carbohydrate completely.

The use of glutamate in therapy of hepatic coma, as suggested by Walshe (24), could be rationalized on the basis of glutamine synthesis, Figure 2, which goes on in kidney and liver, as well as brain. This might indeed be a good basis for its use, but clinical experience has not been uniformly favorable (25).

The use of substances designed to reduce the production of ammonia might offer some promise. This was accomplished by McDermott and Adams (2) by the administration of non-absorbable sulfonamides, which probably had the effect of altering the intestinal flora, with loss of ammonia forming organisms.

\section{SUMMARY AND CONCLUSIONS}

1. Arterial and cerebral venous blood ammonia determinations are reported in normal patients, patients with hepatic disease, and in a variety of diseases in the presence and absence of coma.

2. In hepatic disease, the blood level of ammonia is uniformly elevated, and is roughly proportional to the depth of coma.

3. The brain takes up ammonia when the blood level rises above 1 gamma per $\mathrm{ml}$. The uptake of ammonia by brain is roughly proportional to the arterial concentration.

4. Simultaneous determinations of peripheral venous blood with arterial and cerebral venous blood show a parallel uptake of ammonia by muscle as the arterial level of ammonia rises.

5. A hypothesis for the chemical pathology of hepatic coma is presented, and the suggestion offered that the phenomenon of ammonia intoxication is a part of a number of other syndromes.

\section{ACKNOWLEDGMENT}

The authors wish to thank Drs. W. V. McDermott and Ray Adams for the opportunity to discuss their observations prior to publication (2). The work reported and the hypothesis presented are the outgrowth of these stimulating conversations. 


\section{REFERENCES}

1. Bessman, S. P., and Bessman, A. N., Ammonia poisoning of hepatic coma; cerebral arteriovenous amino acid levels. Federation Proc., 1954, 13, 336.

2. McDermott, W. V., Jr., and Adams, R. D., Episodic stupor associated with an Eck fistula in the human with particular reference to the metabolism of ammonia. J. Clin. Invest., 1954, 33, 1.

3. Phillips, G. B., Schwartz, R., Gabuzda, G. J., Jr., and Davidson, C. S., The syndrome of impending hepatic coma in patients with cirrhosis of the liver given certain nitrogenous substances. New England J. Med., 1952, 247, 239.

4. Bessman, S. P., Fazekas, J. F., and Bessman, A. N., Uptake of ammonia by the brain in hepatic coma. Proc. Soc. Exper. Biol. \& Med., 1954, 85, 66.

5. Seligson, D., and Seligson, H., A microdiffusion method for the determination of nitrogen liberated as ammonia. J. Lab. \& Clin. Med., 1951, 38, 324.

6. Vanselow, A. P., Preparation of Nessler's reagent. Indust. \& Engin. Chem., Anal. Ed., 1940, 12, 516.

7. Conway, E. J., Apparatus for the micro-determination of certain volatile substances. IV. The blood ammonia, with observations on normal human blood. Biochem. J., 1935, 29, 2755.

8. Bessman, S. P., Magnes, J., Schwerin, P., and Waelsch, $H$., The absorption of glutamic acid and glutamine. J. Biol. Chem., 1948, 175, 817.

9. Belitzer, V. A., La Regulation de la Respiration Musculaire par les Transformations du Phosphagène. Enzymologia, 1939, 6, 1.

10. Green, D. E., Atchley, W. A., Nordmann, J., and Teply, L. J., Studies on the cyclophorase system. XII. Incorporation of $\mathrm{P}^{*}$. Arch. Biochem., 1949, 24, 359.

11. Lardy, H. A., and Wellman, H., Oxidative phosphorylations: Rôle of inorganic phosphate and accepter systems in control of metabolic rates. J. Biol. Chem., 1952, 195, 215.
12. Wechsler, R. L., Crum, W., and Roth, J. L. A., The blood flow and $\mathrm{O}_{2}$ consumption of the human brain in hepatic coma. Clin. Research Proc., 1954, $2,74$.

13. Fazekas, J. F., and Bessman, A. N., To be reported.

14. Von Euler, H., Adler, E., Günther, G., and Das, N. B., Uber den Enzymatischen Abbau und Aufbau der Glutaminsäure. Ztschr. f. physiol. Chem., 1938, 254, 5.

15. Potter, V. R., and Recknagel, R. O., Alternative metabolic pathways in rat liver homogenates. Federation Proc., 1950, 9, 215.

16. Bessman, S. P., Glutamate stimulation of malate and fumarate oxidation in brain homogenates. Federation Proc., 1952, 11, 187.

17. Bessman, S. P., Rossen, J., and Layne, E. C., Gammaaminobutyric acid-glutamic acid transamination in brain. J. Biol. Chem., 1953, 201, 385.

18. Embden, G., and Schmidt, G., Uber die Bedeutung der Adenylsäure für die Muskelfunktion VI, Weitere Untersuchungen über die Herkunft des Muskel-ammoniaks. Ztschr. f. physiol. Chem., 1930, 186, 205.

19. Walshe, J. M., Observations on the symptomatology and pathogenesis of hepatic coma. Quart. J. Med., 1951, 20, 421.

20. Nelson, R. M., and Seligson, D., Studies on blood ammonia in normal and shock states. Surgery, 1953, 34, 1.

21. Beaton, J. R., McGanity, W. J., and McHenry, E. W., Plasma glutamic acid levels in malignancy. Canad. M. A. J., 1951, 65, 219.

22. Bessman, A. N., and Evans, J. Mc., To be reported.

23. Seligson, D., McCormick, G. J., and Sborov, V., Blood ketoglutarate and pyruvate in liver disease. J. Clin. Invest., 1952, 31, 661.

24. Walshe, J. M., The effect of glutamic acid on the coma of hepatic failure. Lancet, 1953, I, 1075.

25. Webster, L. T., Jr., and Davidson, C. S., Hepatic coma : Effect of sodium glutamate. J. Clin. Invest., 1954, 33, 971. 